\title{
Mathematical models describing disappearance of Lucerne hay in the rumen using the nylon bag technique
}

\author{
V. Palangi ${ }^{1^{*}}$, M. Macit ${ }^{1}$, A.R. Bayat ${ }^{2}$ \\ ${ }^{1}$ Department of Animal Science, Agricultural Faculty, Ataturk University, 25240, Erzurum, Turkey \\ ${ }^{2}$ Milk Production, Production Systems, Natural Resources Institute Finland (Luke), Jokioinen, 31600, Finland
}

(Submitted 28 May 2020; Accepted 28 July 2020; Published 5 November 2020)

\begin{abstract}
Copyright resides with the authors in terms of the Creative Commons Attribution 4.0 South African Licence.
See: http://creativecommons.org/licenses/by/4.0/za

Condition of use: The user may copy, distribute, transmit and adapt the work, but must recognise the authors and the South African Journal of Animal Science.
\end{abstract}

\begin{abstract}
It is essential to study the dynamics of rumen degradation of feeds before their potential use in formulating diets for ruminants. Various mathematical models have been developed to describe this degradation. The non-lagged exponential model (Model I), the lagged exponential model (Model II), the Gompertz model (Model III), and the generalized Mitscherlich model (Model IV) were examined using two alternative software (SAS and MATLAB) to determine their efficacy in accounting for variation in ruminal disappearance of dry matter (DM) and crude protein (CP) of lucerne hay from three cuttings. All models described DM degradability well $\left(\mathrm{R}^{2}>0.98\right)$. Only Models I and II converged when fitted to CP degradability data $\left(R^{2}>0.98\right)$. It was concluded that any of these models could be used to describe the degradation of DM, whereas only Models I and II could be used to describe the degradation of CP from three cuttings of Lucerne hay. All the models that were fitted to the DM degradation data performed reasonably well, with only minor differences in goodness of fit. However, these models differed in values of the parameter estimates. Additionally, SAS failed to converge in the analyses of CP with Models III and IV, and MATLAB converged to nonsensical values with Model III. Model I might be recommended because it fitted the data well and required estimates of the fewest parameters.
\end{abstract}

Keywords: alfalfa hay, in situ digestion, model selection, nonlinear regression

\#Corresponding author: valiollah.palangi12@ogr.atauni.edu.tr

\section{Introduction}

Forage is an important component of rations for ruminant animals. Lucerne (Medicago sativa L.) is important because of its high protein content and digestibility in comparison with many other forages (Ferdinand \& Jung, 2005). Identification of the quality and nutritional value of these forage plants would be effective in describing animal nutrition (Jeromela et al., 2017; Bi et al., 2018; Besharati et al., 2020). Changes in digestive processes are of nutritional importance, because they determine the quantity of nutrients that are available to the animal (Sauvant \& Noziere, 2016; Van Soest, 2018).

Formulating appropriate diets for ruminants requires detailed descriptions of the nutritional value of feeds and their degradation kinetics in the rumen (Tedeschi, 2019; da Costa et al., 2020). Therefore accurate estimates of degradation parameters are required to fit various mathematical models and to select best fit models for describing the in situ ruminal incubation of feeds. Degradation kinetics can be measured by techniques such as in situ, in vivo and in vitro (Benedeti et al., 2019). The nylon bag technique has been used widely to estimate ruminal nutrient degradation because it is relatively simple and low cost compared with methods that involve intestinally cannulated animals (Tassone et al., 2020).

Non-linear models may help to obtain more accurate descriptions about the degradability of feeds. Various mathematical models have been developed to describe the ruminal degradation kinetics of feeds from data obtained by the in situ technique. The usual model is the simple negative exponential or Mitscherlich model suggested by Ørskov \& McDonald (1979). However, the segmented model (France et al., 1990), the inverse polynomial model (France et al., 1990), the lag compartment model (Van Milgen et al., 1991), the generalized Mitscherlich model (Dhanoa et al., 1995), Gompertz curves model (France et al., 1990), and the generalized Von Bertalanffy model (Ricker, 1979) have been used to describe aspects of digestion kinetics. The best-fit models may differ between feeds (forages and non-forages) and may depend 
on whether a lag phase in degradation is considered (Lopez et al., 1999). Previous studies found that lucerne varies in digestibility and intake, even if it is harvested at a constant maturity (Kawas et al., 1990). The chemical and physical changes in lucerne as a result of increased maturity, and the method of preservation may affect rumen digestion and passage (Nelson \& Satter, 1992).

The objective of this study was to determine in situ the kinetics of DM and CP disappearance in the rumen of various cuttings of Lucerne hay. Degradation parameters were estimated using various mathematical models to identify the best model to describe the data.

\section{Materials and Methods}

Two diminishing returns and two sigmoidal models were used to describe the ruminal degradation of the DM and CP of various cuts of lucerne. Four replicate samples that were being digested in situ were withdrawn for analysis at $0,4,8,12,16,24$, and 48 hours of digestion.

Models I and II are simple negative exponential curve models (monomolecular Mitscherlich or firstorder kinetics models) with and without a lag phase (Ørskov \& McDonald, 1979). Model III is a Gompertz curve, asymmetrical about an inflection point $M$ (France et al., 1990). Model IV is the generalized Mitscherlich model, with the addition of a square root time dependence component (Dhanoa et al., 1995). Mathematically, these models are specified as follows:

Model I: first-order kinetics model without lag phase:

Model II: first-order kinetics model with lag phase:

Model III: Gompertz model:

Model IV: generalized Mitscherlich model:

$$
\begin{aligned}
& Y=a+b\left(1-e^{-c t}\right) \\
& Y=a+b\left(1-e^{c(t+l)}\right) \\
& Y=a+b\left(k-k^{e(c t)}\right) /(k-1) \\
& Y=a+b\left(1-e^{-c(t-l)-d(\sqrt{t}-\sqrt{l})}\right)
\end{aligned}
$$

where: $Y=$ the quantity of either DM or $\mathrm{CP}$,

$a, b, c, d$ and

$k=$ parameters to be estimated, and $t=$ time.

The DM and CP data were fitted to each model by nonlinear regression using the NLIN procedure of SAS (SAS Institute, Inc., Cary, North Carolina, USA). Several probable initial values were provided to calculate an initial residual sum of squares to determine the starting point for iteration. Since some of these models did not converge in SAS, the same models were fitted using MATLAB (The MathWorks Inc., Natick, Massachusetts, USA). An optimization method was used that combined the MATLAB curve fitting toolbox and the numerical algorithm based on the Levenberg-Marquardt method. The models were identified through the editor ToolStrip, and the starting points and ranges required for the models were defined. A goodness of fit measure based on the error values of the fitted curves was used to assess the adequacy of the models. The mean square error and pseudo $R^{2}=1$ - (residual sum of squares / corrected total sum of squares) were used to describe the general goodness-of-fit for each model. Effective degradability (ED) was calculated as:

$$
E D=a+\left(\frac{b c}{c+k}\right)(Ø \text { rskov et al., 1980) }
$$

where: $a, b$ and $c$ are estimates of the parameters from fitting the models and

$k$ is the fractional rate of outflow from the rumen $(0.02 / \mathrm{h}, 0.03 / \mathrm{h}, 0.04 / \mathrm{h}, 0.05 / \mathrm{h}$, and $0.06 / \mathrm{h})$.

\section{Results and Discussion}

The variation in DM increased from the first to the third cuttings. The variation in CP was least in the lucerne from the third cutting and most in the second cutting, with the first cutting samples being intermediate.

A comparison of these fitted models for DM degradability of various cuttings of lucerne hay based on $\mathrm{R}^{2}$ showed that Models IV, III and II were best fit for the data from the first, second and third cuttings, respectively (Table 1). Thus, except for the results from Model I for the third cutting of lucerne, models were all equivalent $(P>0.3)$. The high coefficients of determination indicated the adequacy of their performance. The parameter estimates for time lag in DM digestion from the third cutting were greater than those of the first cutting. Therefore, it could be said that the degradability of third-cut hay takes nine hours to start. This may be because of higher air temperatures in summer, leading to an increase in structural compounds and 
enhanced lignin content, which hinders the launch of microbial degradation. No lag time was observed for the second cutting of lucerne hay, therefore lag times of forages and their composition have a relationship.

Table 1 Estimated parameters describing dry matter degradation of lucerne hay harvested from three cuttings using mathematical models fitted with PROC NLIN of SAS

\begin{tabular}{|c|c|c|c|c|c|c|c|c|c|c|}
\hline & \multicolumn{6}{|c|}{ Parameters } & \multirow{2}{*}{$d f_{e}$} & \multirow{2}{*}{$\mathrm{MS}_{\mathrm{e}}$} & \multirow{2}{*}{$\mathrm{R}^{2}$} & \multirow{2}{*}{1} \\
\hline & $a$ & $b$ & $c$ & $L$ & $d$ & $k$ & & & & \\
\hline \multicolumn{11}{|l|}{ First cutting } \\
\hline Model I & 21.44 & 42.64 & 0.0254 & - & - & - & 25 & 1.12 & 0.9832 & 7 \\
\hline Model II & 23.35 & 39.11 & 0.0295 & 3.3003 & - & - & 24 & 0.85 & 0.9877 & 10 \\
\hline Model III & 22.93 & 36.80 & 0.0509 & - & - & 0.1361 & 24 & 0.82 & 0.9882 & 11 \\
\hline Model IV & 23.35 & 37.64 & 0.0421 & 0.4238 & 0.0831 & - & 23 & 0.84 & 0.9883 & 6 \\
\hline \multicolumn{11}{|c|}{ Second cutting } \\
\hline Model I & 22.99 & 45.47 & 0.0259 & - & - & - & 25 & 1.07 & 0.9856 & 6 \\
\hline Model II & 22.83 & 45.63 & 0.0259 & 0.1375 & - & - & 24 & 1.11 & 0.9856 & 9 \\
\hline Model III & 23.76 & 41.87 & 0.0392 & - & - & 0.3483 & 24 & 1.02 & 0.9871 & 9 \\
\hline Model IV & 22.48 & 42.93 & 0.0307 & 0.0263 & 0.0099 & - & 23 & 1.43 & 0.9828 & 18 \\
\hline \multicolumn{11}{|l|}{ Third cutting } \\
\hline Model I & 19.47 & 53.29 & 0.0197 & - & - & - & 25 & 1.76 & 0.9801 & 7 \\
\hline Model II & 22.98 & 44.19 & 0.0284 & 6.8487 & - & - & 24 & 0.77 & 0.9917 & 7 \\
\hline Model III & 22.00 & 40.98 & 0.0564 & - & - & 0.0422 & 24 & 0.78 & 0.9916 & 17 \\
\hline Model IV & 23.86 & 42.29 & 0.0300 & 8.9265 & 0.0155 & - & 23 & 0.85 & 0.9912 & 12 \\
\hline
\end{tabular}

$a$ : rapidly soluble fraction (\%), $b$ : slowly degradable fraction (\%), $c$ : degradation rate constant (\%/h) of fraction b; $L$ : lag time $(\mathrm{h}), d$ : the parameter pertaining to the variable fractional rate of degradation $k$ : slope, or degradation rate coefficient $\left(h^{-1}\right), \mathrm{df}_{\mathrm{e}}$ : degrees of freedom for error, $\mathrm{MS}_{\mathrm{e}}$ : mean square error, I: number of iterations, Model I: first-order kinetics model without lag phase, Model II: first-order kinetics model with lag phase, Model III: Gompertz model, Model IV: generalized Mitscherlich model

Only Models I and II converged when using SAS to evaluate ruminal CP degradation of lucerne hay from the cuttings (Table 2). These models fit the data for CP degradation equally well $(P>0.4)$.For Model I, the rapidly soluble fraction (a) of CP for the first and third cuttings of lucerne hay was greater than for Model II, whereas this pattern was reversed for the slowly degradable fraction (b). The values of (b) observed in this experiment were higher compared with Taghizadeh et al. (2008), but the values of (a) reported here agree with their results. In contrast, the values of (a) for CP from the current study were lower than those reported by Elizald et al. (1999), whereas the values of (b) were consistent with their data. Observations of DM and CP degradability could depend on differences in the variety of lucerne, drying conditions, climate, soil, plant maturity, sample size, the surface area of the nylon bag, and microbial contamination (Palangi \& Macit, 2019).

A few important differences were noted (Table 3) in using MATLAB to fit the same nonlinear models for DM degradation as was done with SAS, First, the mean square error for from Model II for the first and third cuttings was higher than with SAS and this difference was significant for the third cutting hay $(P=0.02)$. Second, Model III converged with an illogical negative estimate of (a) for the second cutting of lucerne. Finally, there were additional numerical that-might affect biological interpretations of the data. 
Table 2 Estimated parameters describing crude protein degradation lucerne hay harvested from three cuttings using mathematical models fitted with PROC NLIN of SAS

\begin{tabular}{|c|c|c|c|c|c|c|c|c|}
\hline & \multicolumn{4}{|c|}{ Parameters } & \multirow{2}{*}{$\mathrm{df}_{\mathrm{e}}$} & \multirow{2}{*}{$\mathrm{MS}_{\mathrm{e}}$} & \multirow{2}{*}{$\mathrm{R}^{2}$} & \multirow{2}{*}{1} \\
\hline & $a$ & $b$ & $c$ & $L$ & & & & \\
\hline \multicolumn{9}{|l|}{ First cutting } \\
\hline Model I & 8.558 & 62.30 & 0.0186 & - & 25 & 4.30 & 0.9843 & 5 \\
\hline Model II & 0.096 & 70.96 & 0.0186 & 6.99 & 24 & 4.48 & 0.9849 & 6 \\
\hline \multicolumn{9}{|c|}{ Second cutting } \\
\hline Model I & 3.389 & 67.34 & 0.0196 & - & 25 & 2.38 & 0.9874 & 6 \\
\hline Model II & 5.020 & 62.92 & 0.0221 & 2.35 & 24 & 2.25 & 0.9901 & 8 \\
\hline \multicolumn{9}{|l|}{ Third cutting } \\
\hline Model I & 8.425 & 63.02 & 0.0148 & - & 25 & 3.43 & 0.9874 & 7 \\
\hline Model II & 1.602 & 69.84 & 0.0148 & 6.95 & 24 & 3.58 & 0.9901 & 6 \\
\hline
\end{tabular}

a: rapidly soluble fraction (\%), $b$ : slowly degradable fraction (\%), $c$ : degradation rate constant (\%/h) of fraction $b$; L: lag time $(\mathrm{h}), \mathrm{df}_{\mathrm{e}}$ : degrees of freedom for error, $\mathrm{MS}_{\mathrm{e}}$ : mean square error, I: number of iterations, Model I: first-order kinetics model without lag phase, Model II: first-order kinetics model with lag phase

Table 3 Estimated parameters describing dry matter degradation of lucerne hay harvested from three cuttings using mathematical models fitted with MATLAB

\begin{tabular}{|c|c|c|c|c|c|c|c|c|c|c|}
\hline & \multicolumn{6}{|c|}{ Parameters } & \multirow{2}{*}{$d_{f e}$} & \multirow{2}{*}{$\mathrm{MS}_{\mathrm{e}}$} & \multirow{2}{*}{$R^{2}$} & \multirow{2}{*}{1} \\
\hline & $a$ & $B$ & $c$ & $L$ & $d$ & $k$ & & & & \\
\hline \multicolumn{11}{|l|}{ First cutting } \\
\hline Model I & 21.46 & 42.66 & 0.0254 & - & - & - & 25 & 1.12 & 0.9831 & 8 \\
\hline Model II & 26.98 & 37.14 & 0.0254 & 0.1385 & - & - & 24 & 1.17 & 0.9831 & 7 \\
\hline Model III & 12.27 & 36.79 & 0.0510 & - & - & 0.1348 & 24 & 0.81 & 0.9882 & 7 \\
\hline Model IV & 30.09 & 51.15 & 0.0247 & 9.9020 & 0.0460 & - & 23 & 0.87 & 0.9879 & 6 \\
\hline \multicolumn{11}{|c|}{ Second cutting } \\
\hline Model I & 22.99 & 45.46 & 0.0259 & - & - & - & 25 & 1.07 & 0.9859 & 6 \\
\hline Model II & 29.20 & 39.24 & 0.0259 & 0.1470 & - & - & 24 & 1.12 & 0.9859 & 7 \\
\hline Model III & -13.16 & 41.86 & 0.0392 & - & - & 0.3481 & 24 & 1.03 & 0.9871 & 6 \\
\hline Model IV & 29.44 & 41.84 & 0.0258 & 6.0340 & 0.0086 & - & 23 & 1.15 & 0.9860 & 6 \\
\hline \multicolumn{11}{|l|}{ Third cutting } \\
\hline Model I & 19.47 & 53.78 & 0.0195 & - & - & - & 25 & 1.77 & 0.9803 & 5 \\
\hline Model II & 31.61 & 41.64 & 0.0195 & 0.2559 & - & - & 24 & 1.84 & 0.9803 & 7 \\
\hline Model III & 18.01 & 41.36 & 0.0552 & - & - & 0.0461 & 24 & 0.85 & 0.9908 & 9 \\
\hline Model IV & 32.93 & 65.99 & 0.0208 & 15.9400 & 0.0593 & - & 23 & 0.97 & 0.9901 & 4 \\
\hline
\end{tabular}

a: rapidly soluble fraction (\%), $b$ : slowly degradable fraction (\%), $c$ : degradation rate constant (\%/h) of fraction $\mathrm{b}$; $L$ : lag time (h), $d$ : the parameter pertaining to the variable fractional rate of degradation $k$ : slope, or degradation rate coefficient $\left(\mathrm{h}^{-1}\right), \mathrm{df}_{\mathrm{e}}$ : degrees of freedom for error, $\mathrm{MS}_{\mathrm{e}}$ : mean square error, I: number of iterations, Model I: first-order kinetics model without lag phase, Model II: first-order kinetics model with lag phase, Model III: Gompertz model, Model IV: generalized Mitscherlich model

Anomalies were noted (Table 4) when the estimates of parameters from MATLAB that describe CP degradation were observed, First, all four models fitted the data from each of the cuttings equally $(P>0.1)$. For Models I and II the estimates of mean square error were similar to those generated in the analyses using SAS. 
Second, the estimates from Model III were consistently outside the biologically reasonable range. Model III also required an unusually large number of rounds of iteration to converge.

Table 4 Estimated crude protein degradability parameters of lucerne hay harvested at three cuts using several mathematical models with MATLAB

\begin{tabular}{|c|c|c|c|c|c|c|c|c|c|c|}
\hline & \multicolumn{6}{|c|}{ Parameter estimates } & \multirow[b]{2}{*}{$\mathrm{df}_{\mathrm{e}}$} & \multirow[b]{2}{*}{$\mathrm{MS}_{\mathrm{e}}$} & \multirow{2}{*}{$\mathrm{R}^{2}$} & \multirow[b]{2}{*}{1} \\
\hline & $\mathrm{a}$ & $\mathrm{b}$ & c & $\mathrm{L}$ & $d$ & $\mathrm{k}$ & & & & \\
\hline \multicolumn{11}{|l|}{ First cutting } \\
\hline Model I & 8.556 & 62.30 & 0.0186 & - & - & - & 25 & 4.31 & 0.9635 & 24 \\
\hline Model II & 31.40 & 39.45 & 0.0186 & 0.4569 & - & - & 24 & 4.49 & 0.9635 & 12 \\
\hline Model III & -177.4 & 59.87 & 0.0220 & & & 0.7062 & 24 & 4.58 & 0.9628 & 109 \\
\hline Model IV & 15.61 & 53.60 & 0.0185 & 6.371 & -0.0039 & & 23 & 4.68 & 0.9635 & 5 \\
\hline \multicolumn{11}{|c|}{ Second cutting } \\
\hline Model I & 3.387 & 67.45 & 0.0196 & - & - & - & 25 & 2.35 & 0.9833 & 26 \\
\hline Model II & 31.39 & 39.45 & 0.0196 & 0.5364 & - & - & 24 & 2.44 & 0.9833 & 18 \\
\hline Model III & -199.2 & 64.78 & 0.0232 & & & 0.7079 & 24 & 2.55 & 0.9826 & 109 \\
\hline Model IV & 13.06 & 61.92 & 0.0198 & 8.107 & 0.0088 & & 23 & 2.53 & 0.9836 & 5 \\
\hline \multicolumn{11}{|l|}{ Third cutting } \\
\hline Model I & 8.467 & 63.20 & 0.0147 & - & - & - & 25 & 3.44 & 0.9651 & 12 \\
\hline Model II & 31.81 & 39.86 & 0.0147 & 0.4609 & - & - & 24 & 3.59 & 0.9651 & 15 \\
\hline Model III & -189.9 & 60.31 & 0.0175 & & & 0.72 & 24 & 3.70 & 0.9640 & 109 \\
\hline Model IV & 13.44 & 47.46 & 0.0108 & 4.789 & -0.0378 & & 23 & 5.55 & 0.9669 & 7 \\
\hline
\end{tabular}

$a$ : rapidly soluble fraction (\%), $b$ : slowly degradable fraction (\%), $c$ : degradation rate constant (\%/h) of fraction $b$; $L$ : lag time $(\mathrm{h}), \mathrm{d}$ : the parameter pertaining to the variable fractional rate of degradation $k$ : slope, or degradation rate coefficient (h-1), dfe: degrees of freedom for error, MSe: mean square error, I: number of iterations, Model I: first-order kinetics model without lag phase, Model II: first-order kinetics model with lag phase, Model III: Gompertz model, Model IV: generalized Mitscherlich model

Estimates of effective degradability of the lucerne hays varied more with changes in the assumed values of ruminal rate of passage than between the mathematical models (Table 5). Significant differences in degradation of DM and CP are known to exist between samples of Lucerne hay (Von Keyserlingk et al., 1996).Therefore, despite the relatively small variations among the replicates that were observed in the present study, caution is advised against general interpretation of these results. 
Table 5 Estimated effective degradability of dry matter and crude protein of lucerne hay harvested from three cuttings based on parameter estimates from various mathematical models fitted with PROC NLIN of SAS

\begin{tabular}{|c|c|c|c|c|c|c|c|c|c|c|}
\hline & \multicolumn{5}{|c|}{ Dry matter } & \multicolumn{5}{|c|}{ Crude protein } \\
\hline & $\mathrm{k}=0.02$ & $k=0.03$ & $k=0.04$ & $k=0.05$ & $k=0.06$ & $k=0.02$ & $\mathrm{k}=0.03$ & $k=0.04$ & $k=0.05$ & $\mathrm{k}=0.06$ \\
\hline \multicolumn{11}{|l|}{ First cutting } \\
\hline Model I & 45.30 & 40.99 & 38.00 & 35.80 & 34.12 & 38.58 & 32.40 & 28.33 & 25.45 & 23.30 \\
\hline Model II & 46.66 & 42.74 & 39.95 & 37.86 & 36.24 & 34.29 & 27.25 & 22.62 & 19.34 & 16.89 \\
\hline Model III & 49.35 & 46.08 & 43.54 & 41.49 & 39.82 & & & & & \\
\hline Model IV & 48.87 & 45.33 & 42.65 & 40.56 & 38.87 & & & & & \\
\hline \multicolumn{11}{|c|}{ Second cutting } \\
\hline Model I & 48.65 & 44.06 & 40.86 & 38.51 & 36.70 & 36.72 & 30.00 & 25.53 & 22.35 & 19.97 \\
\hline Model II & 48.58 & 43.97 & 40.76 & 38.40 & 36.59 & 38.05 & 31.71 & 27.41 & 24.31 & 21.96 \\
\hline Model III & 51.48 & 47.48 & 44.48 & 42.16 & 40.30 & & & & & \\
\hline Model IV & 48.48 & 44.19 & 41.12 & 38.81 & 37.01 & & & & & \\
\hline \multicolumn{11}{|l|}{ Third cutting } \\
\hline Model I & 45.91 & 40.59 & 37.05 & 34.53 & 32.64 & 35.23 & 29.24 & 25.44 & 22.82 & 20.89 \\
\hline Model II & 48.91 & 44.47 & 41.33 & 38.99 & 37.18 & 31.30 & 24.67 & 20.46 & 17.55 & 15.42 \\
\hline Model III & 52.25 & 48.75 & 45.98 & 43.72 & 41.86 & & & & & \\
\hline Model IV & 49.23 & 45.00 & 41.98 & 39.72 & 37.96 & & & & & \\
\hline
\end{tabular}

k: rate of rumen passage, Model I: first-order kinetics model without lag phase, Model II: first-order kinetics model with lag phase, Model III: Gompertz model, Model IV: generalized Mitscherlich model

\section{Conclusions}

All the models that were fitted to the DM degradation data performed reasonably well, with only minor differences in goodness of fit. However, these models differed in values of the parameter estimates. Additionally, SAS failed to converge in the analyses of CP with Models III and IV, and MATLAB converged to nonsensical values with Model III. Model I might be recommended because it fitted the data well and required estimates of the fewest parameters.

\section{Authors' contributions}

VP collected the data for this study, and conducted the statistical analyses. VP and MM developed the original hypotheses and designed the experiments. ARB collaborated in interpreting the results and finalized the manuscript. All authors have read and approved the finalized manuscript

\section{Conflict of Interest Declaration}

The authors declare that they have no known competing financial interests or personal relationship that could have appeared to influence the work reported in this paper.

\section{Acknowledgments}

The authors wish to express their sincere gratitude to Mrs. Somayyeh Shabestani for her valuable support in the English edition. Authors are thankful to Dr. Saeid Agahian for his technical assistance with MATLAB analysis.

\section{References}

Benedeti, P.D.B., Valadares Filho, S.D.C., Zanetti, D., Silva, F., Silva, B.D.C., Alhadas, H.M. \& de Sales Silva, F.A., 2019. Prediction of in vivo organic matter digestibility of beef cattle diets from degradation parameters estimated from in situ and in vitro incubations. J. Agric. Sci. 1-10. https://doi.org/10.1017/S0021859620000180

Besharati, M., Palangi, V., Niazifar, M., \& Nemati, Z., 2020. Comparison study of flaxseed, cinnamon and lemon seed essential oil additives on quality and fermentation characteristics of lucerne silage. Acta Agric. Slov. 115(2), 455462. https://doi.org/10.14720/aas.2020.115.2.1483

Bi, Y., Zeng, S., Zhang, R., Diao, Q. \& Tu, Y., 2018. Effects of dietary energy levels on rumen bacterial community composition in Holstein heifers under the same forage to concentrate ratio condition. BMC microbial. 18(1), 69. https://doi.org/10.1186/s12866-018-1213-9 
Da Costa, D.A., Lopes, F.C.F., Rebouças, G.M.N., da Costa Carneiro, J., da Gama, M.A.S., de Souza, C.L. \& Saliba, E.D.O.S., 2020. Ruminal fermentation and degradation, kinetic flow of digesta and milk fatty acid composition of cows fed sugarcane silage-based diets supplemented with whole cottonseed. Semina: Cien. Agrar. 41(4), 13171334. https://doi.org/10.5433/1679-0359.2020v41n4p1317

Dhanoa, M.S., France, J., Siddons, R.C., Lopez, S. \& Buchanan, S.J.G., 1995. A non-linear compartmental model to describe for age degradation kinetics during incubation in polyester bags in the rumen. British J. Nut. 73, 3-15. https://doi.org/10.1079/BJN19950004

Dhanoa, M.S., France, J., Crompton, L.A., Mauricio, R.M., Kebreab, E., Mills, J.A.N., Sanderson, R., Dijkstra, J. \& Lopez, S., 2004. A proposed method to determine the extent of degradation of a feed in the rumen from the degradation profile obtained with the in vitro gas production technique using feces as the inoculum. J. Anim. Sci. 82, 733-746.

Elizalde, J.C., Merchen, N.R. \& Faulkner, D.B., 1999. In situ dry matter and crude protein degradation of fresh forages during the spring growth. J. Dairy Sci. 82, 1978-1990. https://doi.org/10.3168/jds.S0022-0302(99)75434-2

Ferdinand, M.E. \& Jung, H.G., 2005. Alfalfa stem tissues: Impact of lignification and cell length on ruminal degradation of large particles. Anim. Feed Sci. Technol. 120, 309-321. https://doi.org/10.1016/j.anifeedsci.2005.03.003

France, J., Thornley, J.H.M., Lopez, S., Siddons, R.C., Dhanoa, M.S., Van Soest, P.J. \& Gill, M., 1990. On the twocompartment model for estimating extent of feed degradation in the rumen. J. Theor. Biol. 146, 269-287. https://doi.org/10.1016/S0022-5193(05)80139-0

Jeromela, A.M., Mikić, A.M., Vujić, S., Ćupina, B., Krstić, Đ., Dimitrijević, A. \& Miladinović, D., 2017. Potential of legumeBrassica intercrops for forage production and green Manure: encouragements from a temperate southeast European environment. Front. Plant Sci. 8, 312. https://doi.org/10.3389/fpls.2017.00312

Kawas, J.R., Jorgensen, N.A. \& Lu, C.D., 1990. Influence of alfalfa maturity on feed intake and site of nutrient digestion in sheep. J. Anim. Sci. 68, 4376-4386. https://doi.org/10.2527/1990.68124376x

Lopez, S., France, J., Dhanoa, M.S., Mould, F. \& Dijkstra, J., 1999. Comparison of mathematical models to describe disappearance curves obtained using the polyester bag technique for incubating feeds in the rumen. J. Anim. Sci. 77, 1875-1888. https://doi.org/10.2527/1999.7771875x

Mesgaran, M.D., 2003. Ruminal and intestinal protein disappearance of some tropical (Iranian) feeds used in dairy cow diets estimated by the mobile nylon bag technique. Proc. Br. Soc. Anim. Sci., 118.

Nelson, W.F. \& Satter, L.D. 1992. Impact of stage of maturity and method of preservation of alfalfa on digestion in lactating dairy cows. J. Dairy Sci. 75, 1571-1580. https://doi.org/10.3168/jds.S0022-0302(92)77914-4

Ørskov, E.R.I. \& McDonald, I.M., 1979. The estimation of protein degradability in the rumen from incubation measurements weighted according to rate of passage. J. Agric. Sci. 92, 499-503. https://doi.org/10.1017/S0021859600063048

Ørskov, E.R, Hovel, F.D.B. \& Mould, F.L., 1980. The use of the nylon bag technique for evaluation of feedstuffs. Trop. Anim. Prod. 5, 195-213.

Palangi, V. \& Macit, M., 2019. In situ crude protein and dry matter ruminal degradability of heat-treated barley. Revue Méd. Vét. 170, 123-128.

Ricker, W.E., 1979. Growth rates and models. In: W.S. Hoar, D.J. Randall \& J.R. Brett (eds.) Fish physiology. Vol. VIII. Academic Press, New York. Pp 677-743.

Sauvant, D. \& Noziere, P., 2016. Quantification of the main digestive processes in ruminants: the equations involved in the renewed energy and protein feed evaluation systems. Animal. 10(5), 755-770. https://doi.org/10.1017/S1751731115002670

Taghizadeh, A., Safamehr, A., Palangi, V. \& Mehmannavaz, Y., 2008. The determination of metabolizable protein of some feedstuffs used in ruminant. Res. J. Biol. Sci. 3, 804-806. http://medwelljournals.com/abstract/?doi=rjbsci.2008.804.806

Tassone, S., Fortina, R. \& Peiretti, P.G., 2020. In vitro techniques using the Daisy" incubator for the assessment of digestibility: A review. Animals 10(5), 775. https://doi.org/10.3390/ani10050775

Tedeschi, L.O., 2019. ASN-ASAS symposium: Future of data analytics in nutrition: Mathematical modeling in ruminant nutrition: Approaches and paradigms, extant models, and thoughts for upcoming predictive analytics. J. Anim. Sci. 97(5), 1921-1944. https://doi.org/10.1093/jas/skz092

Van Milgen, J., Murphy, M.R. \& Berger, L.L., 1991. A compartmental model to analyze ruminal digestion. J. Dairy Sci. 74(8), 2515-2529. https://doi.org/10.3168/jds.S0022-0302(91)78429-4

Van Soest, P.J., 2018. Nutritional ecology of the ruminant. 2nd edition. Cornell University Press, Ithaca, New York.

Von Keyserlingk, M.A.G., Swift, M.L., Puchala, R. \& Shelford, J.A., 1996. Degradability characteristics of dry matter and crude protein of forages in ruminants. Anim. Feed Sci. Tech. 57, 291-311. 